\title{
Acute Effects of 3,4-Methylenedioxymethamphetamine and Methylphenidate on Circulating Steroid Levels in Healthy Subjects
}

\author{
Julia Seibert $^{\mathrm{a}}$ Cédric M. Hysek ${ }^{\mathrm{b}}$ Carlos A. Penno $^{\mathrm{a}}$ Yasmin Schmid $^{\mathrm{b}}$ \\ Denise V. Kratschmar ${ }^{\mathrm{a}}$ Matthias E. Liechti ${ }^{\mathrm{b}}$ Alex Odermatt $^{\mathrm{a}}$ \\ a Swiss Center for Applied Human Toxicology and Division of Molecular and Systems Toxicology, Department of Pharmaceutical \\ Sciences, University of Basel, and ' Psychopharmacology Research Group, Division of Clinical Pharmacology and Toxicology, \\ Department of Biomedicine and Department of Clinical Research, University Hospital and University of Basel, Basel, Switzerland
}

\section{Key Words}

MDMA $\cdot$ Methylphenidate $\cdot$ Steroid $\cdot$ Cortisol $\cdot$ Aldosterone $\cdot$

Testosterone

\begin{abstract}
3,4-Methylenedioxymethamphetamine (MDMA, 'ecstasy') and methylphenidate are widely used psychoactive substances. MDMA primarily enhances serotonergic neurotransmission, and methylphenidate increases dopamine but has no serotonergic effects. Both drugs also increase norepinephrine, resulting in sympathomimetic properties. Here we studied the effects of MDMA and methylphenidate on 24-hour plasma steroid profiles. 16 healthy subjects ( 8 men, 8 women) were treated with single doses of MDMA (125 mg), methylphenidate (60 mg), MDMA + methylphenidate, and placebo on 4 separate days using a cross-over study design. Cortisol, cortisone, corticosterone, 11-dehydrocorticosterone, aldosterone, 11-deoxycorticosterone, dehydroepiandrosterone (DHEA), dehydroepiandrosterone sulfate (DHEAS), androstenedione, and testosterone were
\end{abstract}

J. Seibert, C.M. Hysek, M.E. Liechti and A. Odermatt contributed equally to this work.

\section{KARGER}

๑) 2014 S. Karger AG, Basel

$0028-3835 / 14 / 1001-0017 \$ 39.50 / 0$

E-Mail karger@karger.com

www.karger.com/nen repeatedly measured up to $24 \mathrm{~h}$ using liquid chromatography-tandem mass spectroscopy. MDMA significantly increased the plasma concentrations of cortisol, corticosterone, 11-dehydrocorticosterone, and 11-deoxycorticosterone and also tended to moderately increase aldosterone levels compared with placebo. MDMA also increased the sum of cortisol + cortisone and the cortisol/cortisone ratio, consistent with an increase in glucocorticoid production. MDMA did not alter the levels of cortisone, DHEA, DHEAS, androstenedione, or testosterone. Methylphenidate did not affect any of the steroid concentrations, and it did not change the effects of MDMA on circulating steroids. In summary, the serotonin releaser MDMA has acute effects on circulating steroids. These effects are not observed after stimulation of the dopamine and norepinephrine systems with methylphenidate. The present findings support the view that serotonin rather than dopamine and norepinephrine mediates the acute pharmacologically induced stimulation of the hypothalamic-pituitary-adrenal axis in the absence of other stressors.

(c) 2014 S. Karger AG, Basel
Matthias E. Liechti

Division of Clinical Pharmacology and Toxicology

University Hospital Basel, Hebelstrasse 2

$\mathrm{CH}-4031$ Basel (Switzerland)

E-Mail matthias.liechti@usb.ch

Alex Odermatt

Division of Molecular and Systems Toxicology

Department of Pharmaceutical Sciences, University of Basel, Klingelbergstrasse 50 $\mathrm{CH}-4056$ Basel (Switzerland)

E-Mail alex.odermatt@unibas.ch 


\section{Introduction}

Many recreational drugs activate the hypothalamicpituitary-adrenal (HPA) axis to release adrenocorticotropic hormone (ACTH) and corticosteroids [1]. The neurochemical mechanisms involved in HPA axis activation depend on the particular drug and mostly involve corticotropin-releasing factor stimulation in the hypothalamus [1-3]. HPA axis activation by cocaine and amphetamine and its derivatives is thought to be mediated by increases in brain monoamines, including dopamine (DA), norepinephrine (NE), and serotonin (5-hydroxytryptamine, 5-HT) [1]. Few studies have examined which of these monoamines contribute the most to HPA axis activation in animals [1], and even less data are available for humans. For example, cocaine inhibits the uptake of all three monoamines (DA, NE, and 5-HT), and all three may be involved in cocaine-induced HPA axis activation. Dopaminergic and adrenergic receptor antagonists reduced the corticosterone response to cocaine in rodents [4-6]. Additionally, the blockade of 5 -HT receptors also decreased the ACTH response to cocaine in rats [5].

3,4-Methylenedioxymethamphetamine (MDMA; 'ecstasy') primarily releases 5 -HT in the brain via the serotonin transporter (SERT) and NE via the NE transporter (NET) [7]. Methylphenidate is an amphetamine derivative used for the treatment of attention-deficit/hyperactivity disorder and misused as a cognitive enhancer and recreationally. In contrast to MDMA, methylphenidate only elevates the levels of DA and NE by inhibiting the DA transporter and NET [8]. Thus, both MDMA and methylphenidate share an enhancing effect on NE neurotransmission, resulting in sympathomimetic and psychostimulant effects [9], but they are otherwise indirect serotonergic or dopaminergic agonists, making them pharmacological tools to evaluate the role of 5-HT and DA as activators of the HPA axis.

Several studies evaluated the stimulant effects of MDMA on the HPA axis in humans [for reviews, see 10, 11]. Plasma cortisol has been shown to be increased after MDMA administration in many human laboratory studies [12-15] and in recreational ecstasy users following MDMA administration in a club setting $[16,17]$. Small laboratory studies also previously reported MDMA-induced increases in ACTH [18] and dehydroepiandrosterone (DHEA) [12]. A trend toward an increase in testosterone was also found in subjects who used MDMA at a dance club [16]. However, the effects of MDMA on a wider range of corticosteroids have not yet been studied in humans. Therefore, we evaluated the acute effects of predominantly 5-HT activation using MDMA or predominantly DA activation using methylphenidate or MDMA + methylphenidate on changes in the plasma concentration of a series of steroids over $24 \mathrm{~h}$ in healthy subjects. Specifically, we measured the plasma levels of glucocorticoids (cortisol, cortisone, corticosterone, and 11-dehydrocorticosterone), mineralocorticoids (aldosterone and 11-deoxycorticosterone), and androgens (DHEA, DHEA sulfate (DHEAS), androstenedione, and testosterone). Cortisol is the main active glucocorticoid and a major stress hormone. It is converted to the inactive metabolite cortisone. Corticosterone is also a potent activator of glucocorticoid and mineralocorticoid receptors, but it is present at 10 - to 20-times lower concentrations than cortisol in humans. 11-Deoxycorticosterone is a precursor of corticosterone and aldosterone and exhibits mineralocorticoid activity [19]. Mineralocorticoids increase renal sodium absorption and blood pressure. Androgens may modulate the addictive effects of drugs of abuse [12, 20,21]. We hypothesized that methylphenidate and MDMA would differentially affect the plasma levels of these steroids based on their different pharmacological profiles.

\section{Methods}

\section{Study Design}

The study used a double-blind, placebo-controlled, cross-over design with four experimental test sessions (placebo-placebo, methylphenidate-placebo, placebo-MDMA, and methylphenidate-MDMA) performed in counterbalanced order according to a Latin square randomization scheme. All of the subjects received all of the study treatments in a within-subjects study design. The washout periods between sessions were at least 10 days. The study was conducted in accordance with the Declaration of Helsinki and International Conference on Harmonization Guidelines in Good Clinical Practice and approved by the local Ethics Committee and Swiss Agency for Therapeutic Products (Swissmedic). The study was registered at ClinicalTrials.gov: http://clinicaltrials.gov/ct2/ show/NCT01465685. All of the subjects provided written informed consent.

\section{Participants}

Sixteen healthy subjects ( 8 men and 8 women; mean \pm SD age $24.8 \pm 2.6$ years) were recruited from the University of Basel campus. The exclusion criteria were acute or chronic physical illness, psychiatric disorders, smoking, and a lifetime history of using illicit drugs more than 5 times, with the exception of past cannabis use. The use of any illicit drugs, including cannabis, within the past 2 months or during the study period was prohibited. We performed urine drug tests at screening and before each test session using Triage ${ }^{\circledR} 8$ (Biosite, San Diego, Calif., USA). Female participants were investigated during the follicular phase of their men-
18

Neuroendocrinology 2014;100:17-25 DOI: $10.1159 / 000364879$
Seibert/Hysek/Penno/Schmid/ Kratschmar/Liechti/Odermatt 
strual cycle (days 2-14) to account for cyclic changes in the reactivity to amphetamines. A detailed description of the participants has been previously published [9].

\section{Study Procedures}

Methylphenidate (60 mg, Ritalin ${ }^{\circledR}$; Novartis, Bern, Switzerland) or placebo was administered orally at 08:00 h. MDMA (125 mg, racemic MDMA hydrochloride; Lipomed, Arlesheim, Switzerland) or placebo was administered orally at 09:00 h. A standardized lunch was served at 12:00 h, and the subjects were sent home at 18:00 h. The day following each test session, the participants returned to the research ward at 09:00 h for the collection of the 24-hour blood sample. The subjects did not engage in any physical activity and were resting in hospital beds during the test session. Blood samples for the analysis of plasma steroid hormone levels (cortisol, cortisone, corticosterone, 11-dehydrocorticosterone, 11-deoxycorticosterone, aldosterone, DHEA, DHEA-S, androstenedione, and testosterone) were collected $1 \mathrm{~h}$ prior to MDMA or placebo administration and $0,0.33,0.67,1,1.5,2,2.5,3,3.5,4,6,8$, and $24 \mathrm{~h}$ following the administration of MDMA or placebo. The psychotropic and autonomic effects of MDMA and methylphenidate from the present study have been presented elsewhere [9].

\section{Steroid Quantification}

A detailed description of the materials, procedure, and method validation is included in the see online supplementary material (for all online suppl. material, see www.karger.com/ doi/10.1159/000364879). Briefly, plasma samples (1 ml) were mixed with $200 \mu \mathrm{l}$ precipitation solution $(0.8 \mathrm{M}$ zinc sulfate in water/methanol and deuterium-labeled aldosterone, cortisol, corticosterone, and testosterone as internal standards), diluted with water to $2 \mathrm{ml}$ and centrifuged again. The supernatants were subjected to Oasis HBL SPE cartridges for purification. The samples were reconstituted in $25 \mu \mathrm{l}$ methanol. Steroids were separated and quantified by ultra-pressure liquid chromatography-tandem mass spectroscopy (UPLC-MS/MS) using an Agilent 1290 UPLC coupled to an Agilent 6490 triple quadrupole MS equipped with an electrospray ionization source (Agilent Technologies, Basel, Switzerland). The separation of analytes was achieved using a reverse-phase column (ACQUITY UPLC ${ }^{\mathrm{TM}} \mathrm{BEH} \mathrm{C}_{18}, 1.7 \mu \mathrm{m}, 2.1$, $150 \mathrm{~mm}$; Waters, Wexford, Ireland). Mass Hunter software (Agilent Technologies) was used for data acquisition and analysis. For method validation, see online supplementary material.

\section{Statistical Analyses}

Peak concentration $\left(\mathrm{C}_{\max }\right)$ values were determined for all repeated measures. Repeated-measures analyses of variance (ANOVAs) with the within-subject factors MDMA (MDMA vs. placebo) and methylphenidate (methylphenidate vs. placebo), followed by the Tukey post hoc tests based on significant main effects of interactions in the ANOVA were used to assess differences in the effect of the different treatment conditions. Associations were assessed using Spearman's rank correlations. One subject was excluded from the correlational analyses because of missing values. Because the effects of MDMA were similar regardless of whether MDMA was administered alone or combined with methylphenidate, the data were pooled for the correlational analyses $(n=30)$. The significance level was set to $\mathrm{p}=0.05$. The statistical analysis was performed using R project statistical packages ( $\mathrm{R}$ Foundation for Statistical Computing, Vienna, Austria).

Effects of MDMA and Methylphenidate on Steroid Hormones

\section{Results}

The peak levels of plasma steroid hormone concentrations and statistics are shown in table 1. MDMA significantly increased the plasma levels of the glucocorticoids cortisol, corticosterone, and 11-dehydrocorticosterone and mineralocorticoid 11-deoxycorticosterone compared with placebo (fig. 1a, c-e) but not the glucocorticoid cortisone (fig. 1b). MDMA also significantly increased the sum of cortisol + cortisone and cortisol/cortisone ratio (table 1). The sum of corticosterone + 11-dehydrocorticosterone was also significantly elevated (data not shown), further supporting the increase in glucocorticoid production. The levels of the mineralocorticoid aldosterone were increased by MDMA (significant main effect) but this effect was only significant for the MDMA + methylphenidate condition compared with placebo (fig. 1f). MDMA did not significantly alter the circulating levels of the androgens DHEA, DHEAS, androstenedione, or testosterone (fig. 2a-e). For unknown reasons the absolute values obtained for DHEAS were lower than expected, allowing qualitative comparison only. Methylphenidate did not affect any of the measured glucocorticoid, mineralocorticoid, or androgen hormones compared with placebo (fig. 1, 2). Administration of MDMA + methylphenidate led to similar hormonal responses compared with MDMA alone (fig. 1,2), with the exception of a more robust and significant increase in aldosterone. There were no interactive effects of MDMA and methylphenidate on steroid levels. As expected, testosterone levels were lower in women than in men. No sex differences were observed in the effects of the drugs on steroid levels. However, significant positive correlations were found between the MDMA-induced peak elevation of 11-deoxycorticosterone and aldosterone and the peak increase in systolic blood pressure $\left(\mathrm{R}_{\mathrm{s}}=0.38\right.$ and 0.40 , respectively, both $\left.\mathrm{p}<0.05, \mathrm{n}=30\right)$ [9]. None of the steroid levels (peak or area under the concentration-time curve changes from baseline) correlated with the simultaneously recorded psychotropic effects of MDMA including 'good drug effects', 'drug liking', 'drug high', 'happy', and 'stimulated' that have been reported previously [9]. The time from MDMA administration to $\mathrm{C}_{\max }$ for cortisol, corticosterone, 11-dehydrocorticosterone, 11-deoxycorticosterone, and aldosterone was $2.1 \pm$ $0.8,1.8 \pm 0.6,2.0 \pm 0.6,1.5 \pm 0.5 \mathrm{~h}$ and $2.1 \pm 1.5 \mathrm{~h}$ (mean \pm $\mathrm{SD}$ ), respectively. The time to $\mathrm{C}_{\max }$ for MDMA was $2.4 \pm$ $0.4 \mathrm{~h}$ [9]. The MDMA-induced acute increases in circulating steroids generally disappeared within $6 \mathrm{~h}$ after drug administration. The plasma levels of cortisol, determined by UPLC-MS/MS (present findings) or radioimmunoas- 
Table 1. Absolute peak plasma steroid concentrations and statistics

\begin{tabular}{|c|c|c|c|c|c|c|c|c|c|c|}
\hline & $\begin{array}{l}\text { Placebo- } \\
\text { placebo } \\
(\text { mean } \pm \mathrm{SE})\end{array}$ & $\begin{array}{l}\text { Placebo- } \\
\text { MDMA } \\
(\text { mean } \pm \text { SE) }\end{array}$ & $\begin{array}{l}\text { Methylphenidate- } \\
\text { placebo } \\
(\text { mean } \pm \text { SE })\end{array}$ & $\begin{array}{l}\text { Methylphenidate- } \\
\text { MDMA } \\
(\text { mean } \pm \text { SE) }\end{array}$ & $\mathrm{F}_{1,16}$ & $\mathrm{p}$ value & $\mathrm{F}_{1,16}$ & $\mathrm{p}$ value & $\mathrm{F}_{1,16}$ & $\mathrm{p}$ value \\
\hline \multicolumn{11}{|l|}{ Glucocorticoids } \\
\hline Cortisol, nM & $463 \pm 53$ & $770 \pm 45^{* * *}$ & $556 \pm 54$ & $765 \pm 43^{* * *}$ & 43.47 & $<0.001$ & 3.05 & 0.10 & 2.39 & 0.14 \\
\hline Cortisone, $\mathrm{nM}$ & $36.7 \pm 1.8$ & $40.9 \pm 2.7$ & $43.4 \pm 3.0$ & $42.6 \pm 2.2$ & 0.34 & 0.57 & 3.65 & 0.08 & 1.39 & 0.26 \\
\hline Cortisol + cortisone & $499 \pm 52$ & $796 \pm 45^{* * *}$ & $582 \pm 54^{\# \# \#}$ & $802 \pm 43^{* * *}$ & 43.47 & $<0.001$ & 3.05 & 0.10 & 1.46 & 0.25 \\
\hline Cortisol/cortisone ratio & $15.8 \pm 1.7$ & $24.8 \pm 1.5^{* * *}$ & $16.6 \pm 1.5^{\# \# \#}$ & $23.21 \pm 1.46^{* * *}$ & 26.77 & $<0.001$ & 0.29 & 0.60 & 1.24 & 0.28 \\
\hline \multicolumn{11}{|l|}{ Mineralocorticoids } \\
\hline Aldosterone, $\mathrm{nM}$ & $0.16 \pm 0.04$ & $0.25 \pm 0.06$ & $0.17 \pm 0.04$ & $0.33 \pm 0.11^{*}$ & 5.56 & 0.03 & 1.02 & 0.33 & 1.14 & 0.30 \\
\hline 11-Deoxycorticosterone, nM & $0.21 \pm 0.06$ & $0.42 \pm 0.08^{* *}$ & $0.26 \pm 0.07^{\#}$ & $0.44 \pm 0.08^{* * *}$ & 14.57 & 0.002 & 0.86 & 0.37 & 0.16 & 0.69 \\
\hline \multicolumn{11}{|l|}{ Androgens } \\
\hline Testosterone in men, $\mathrm{nM}$ & $11.8 \pm 4.4$ & $13.0 \pm 3.9$ & $14.0 \pm 4.3$ & $13.0 \pm 4.0$ & $0.00^{\mathrm{a}}$ & 0.97 & $2.35^{\mathrm{a}}$ & 0.17 & $3.03^{\mathrm{a}}$ & 0.13 \\
\hline
\end{tabular}

Values are peak concentrations (mean \pm SEM) of 16 subjects. ${ }^{*}$ For $\mathrm{p}<0.05,{ }^{* *}$ for $\mathrm{p}<0.01$, and ${ }^{* * *}$ for $\mathrm{p}<0.001$ compared to placebo-placebo. ${ }^{\#}$ For $\mathrm{p}<0.05$, and ${ }^{\# \# \#}$ for $\mathrm{p}<0.001$ compared to placebo-MDMA (Tukey post hoc tests based on significant main effects in the ANOVAs).

${ }^{a} \mathrm{~F}_{1,7}$ (8 instead of 16 subjects).

say [9], at the $2 \mathrm{~h}$ time point after MDMA administration were significantly correlated across all measurements $\left(\mathrm{R}_{\mathrm{s}}=0.77, \mathrm{p}<0.001\right.$, respectively, $\left.\mathrm{n}=64\right)$.

\section{Discussion}

The present study provides insights into the acute effects of two sympathomimetic drugs or pharmacological stressors on the plasma levels of a series of steroids in healthy humans. MDMA increased the plasma levels of the glucocorticoid cortisol. MDMA also increased the plasma levels of corticosterone and the inactive steroid 11-dehydrocorticosterone, which is known to change in parallel with cortisol [22]. Although circulating concentrations of corticosterone are lower than those of cortisol, a significantly increased ratio of corticosterone to cortisol was observed in the brain as a result of differential transport by the P-glycoprotein at the blood-brain barrier [23]. MDMA had no effect on the inactive cortisol metabolite cortisone, which is produced by $11 \beta$-hydroxysteroid dehydrogenase ( $11 \beta$-HSD) type 2 , mainly in the kidney, and the reverse reaction is catalyzed by $11 \beta-\mathrm{HSD} 1$ [24]. Notably, MDMA increased both the sum of cortisol + cortisone levels and cortisol/cortisone ratio, suggesting an increase in HPA axis stimulation and possibly reduced or saturated $11 \beta$-HSD2 enzyme function [25]. A high cortisol/cortisone ratio has also been observed after acute ACTH administration and in patients with chronic ACTH hypersecretion [25]. In contrast, a low cortisol/cortisone ratio characterizes adrenal insufficiency [26]. MDMA also increased the levels of the mineralocorticoids 11-deoxycorticosterone and aldosterone, an effect that reached significance for the latter only when MDMA was co-administered with methylphenidate. The mineralocorticoids, including aldosterone and 11-deoxycorticosterone, physiologically increase renal sodium absorption and blood pressure. We observed a significant association between MDMA-induced increases in mineralocorticoids and increases in systolic blood pressure. However, MDMA does not alter plasma sodium levels or plasma osmolality as shown in a previous study [27]. This finding would be well explained by the fact that MDMA also increases plasma arginine vasopressin $[27,28]$, which increases water retention and therefore has similar effects on blood pressure as aldosterone but opposite effects on plasma sodium levels. In fact, MDMA tended to increase urine osmolality [27]. In the present study, MDMA did not affect the concentrations of the androgens DHEA, DHEAS, androstenedione, or testosterone. Methylphenidate alone did not increase 


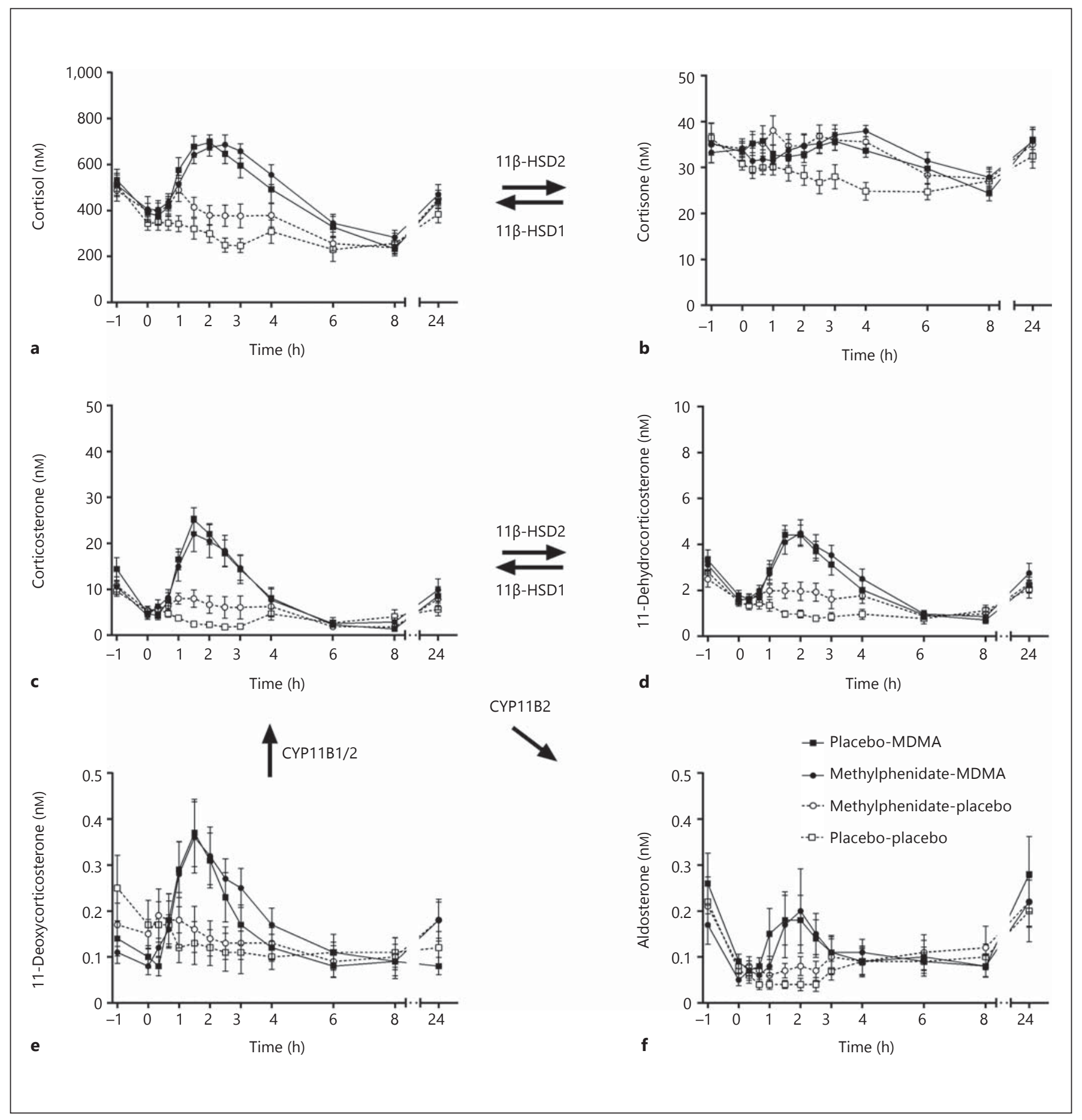

Fig. 1. a-f Effects of MDMA and methylphenidate on plasma concentration-time profiles of glucocorticoids and mineralocorticoids. The values are expressed as mean \pm SEM in 16 subjects. MDMA was administered at $\mathrm{t}=0 \mathrm{~h}$. Methylphenidate was administered at $\mathrm{t}=-1 \mathrm{~h}$. MDMA significantly increased the plasma concentrations of cortisol (a), corticosterone (c), 11-dehydrocorticosterone (d), and weak mineralocorticoid 11-deoxycorticosterone (e) but not the non-bioactive glucocorticoid cortisone (b). MDMA also tended to moderately increase the plasma levels of the mineralocorticoid aldosterone (f). Similar changes in plasma steroid levels were induced regardless of whether MDMA was administered alone or combined with methylphenidate (a-f). In contrast to MDMA, methylphenidate did not alter the plasma levels of any of the steroids (a-f). CYP $=$ Cytochrome P450. 


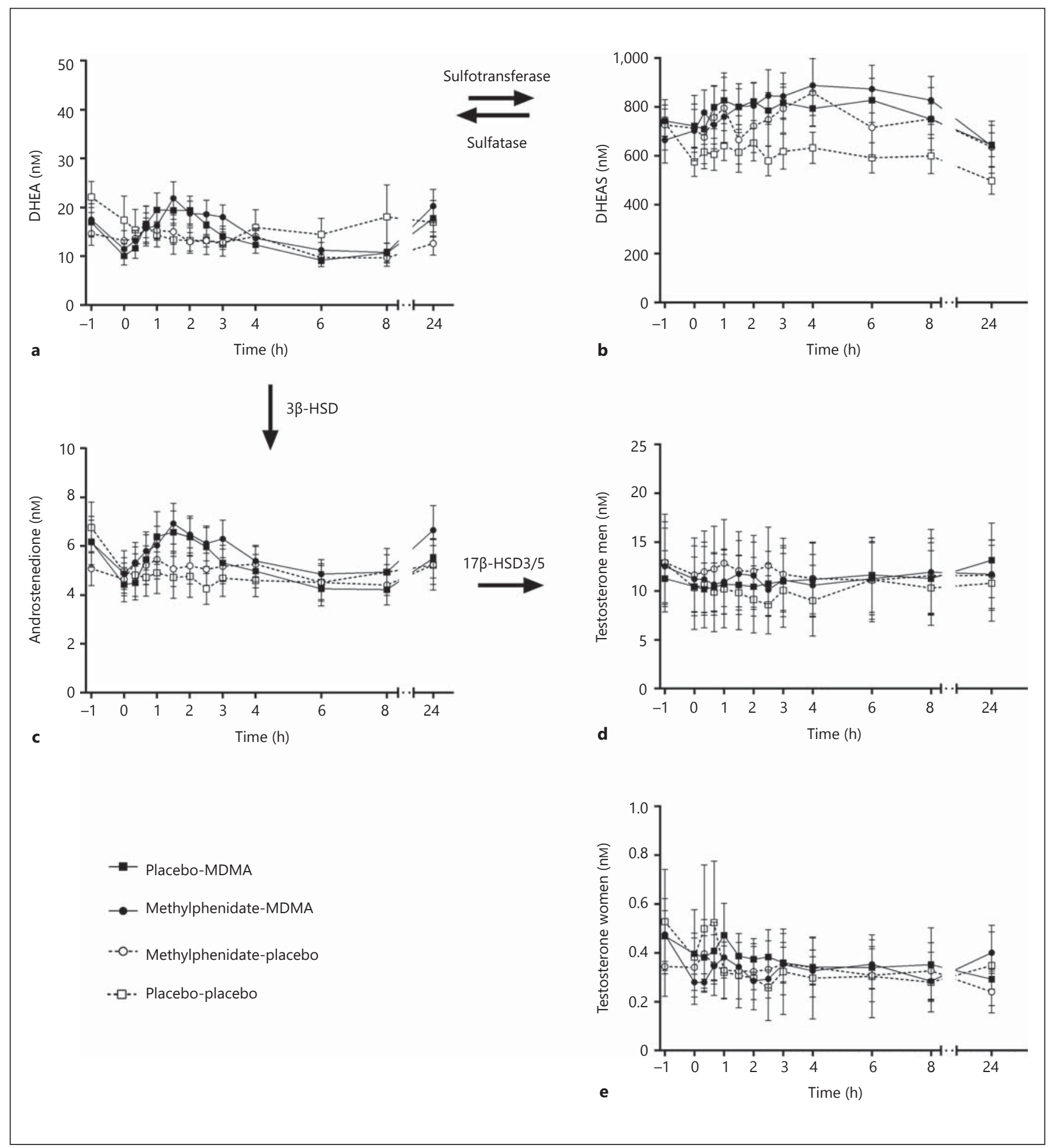

Fig. 2. Effects of MDMA and methylphenidate on plasma concentration-time profiles of androgens. The values are expressed as the mean \pm SEM in 16 subjects (8 subjects for testosterone). MDMA was administered at $\mathrm{t}=0 \mathrm{~h}$. Methylphenidate was administered at $\mathrm{t}=-1 \mathrm{~h}$. MDMA did not significantly alter the plasma concentrations of DHEA (a), DHEAS (b), androstenedione (c), or testos- terone in men (d) or women (e). Similar changes in plasma androgen levels were induced regardless of whether MDMA was administered alone or combined with methylphenidate (a-e). Similarly, methylphenidate did not alter the plasma levels of any of the androgens (a-e). 17 $\beta$-HSD $=17 \beta$-Hydroxysteroid dehydrogenase. 
the concentrations of any of the steroids measured. Coadministration of MDMA + methylphenidate produced a similar hormonal response to MDMA alone.

Several previous laboratory studies have documented similar and maximal 2-fold (50-100\%) increases in plasma cortisol levels in response to comparable doses of MDMA [12-15]. In contrast, 2- to 8-fold increases in cortisol levels were observed in dance clubbers who used MDMA while physically active [16, 17, 29]. Moderate MDMA-induced elevations of DHEA were seen in a previous laboratory study [12]. The effects of MDMA on all of the other steroids reported herein have not been previously described in a placebo-controlled setting. A nonsignificant trend toward an increase in plasma testosterone levels has been reported in healthy subjects who used MDMA at a dance club [16]. In contrast, we did not observe any effects of MDMA on testosterone levels in our placebo-controlled study.

Methylphenidate at an oral dose of $60 \mathrm{mg}$ did not affect steroid levels in the present study. Similarly, oral methylphenidate at a dose of $20 \mathrm{mg}$ did not alter plasma cortisol levels in healthy subjects [30,31]. In contrast, intravenous methylphenidate at doses of $10 \mathrm{mg}(0.12-0.15 \mathrm{mg} / \mathrm{kg})$ or $0.3 \mathrm{mg} / \mathrm{kg}$ significantly increased cortisol levels in healthy subjects [32]. Related catecholaminergic substances, such as amphetamine and methamphetamine, have also been shown to elevate cortisol levels in some studies [33-36] but not others [14]. A single dose of the NET inhibitor reboxetine also increased cortisol levels [37], particularly in subjects who scored high on subclinical depression [38]. Chronic treatment with methylphenidate increased the levels of DHEA and DHEAS but not cortisol in children with attention-deficit/hyperactivity disorder [39]. There are several possible explanations why methylphenidate at a relatively high single oral dose of $60 \mathrm{mg}$ [40, 41] did not affect steroid levels in the present study. For example, cortisol levels are typically highest in the morning, which is when methylphenidate was administered in our study. In contrast, in studies that reported significant increases in cortisol, methylphenidate was administered in the evening, when cortisol levels are typically low [32]. Additionally, physical activity may have enhanced the response to stimulant drugs in some previous studies [29], whereas our subjects were resting. Finally, a significant response was observed with intravenous but not oral administration, possibly because of faster changes associated with the mode of drug exposure.

Pharmacologically, MDMA activates the 5-HT system, and methylphenidate does not [7]. MDMA but not methylphenidate increased plasma prolactin levels [9], which is

Effects of MDMA and Methylphenidate on Steroid Hormones a clinical marker of serotonergic activity [42]. The present study, therefore, indicates that 5-HT plays a crucial role in mediating activation of the HPA axis. In rats, the MDMAinduced release of ACTH or corticosterone has been shown to involve 5 - $\mathrm{HT}$ release and $5-\mathrm{HT}_{1}$ and $5-\mathrm{HT}_{2}$ receptor stimulation $[43,44]$. We previously showed that MDMA-induced increases in plasma cortisol in humans were blocked by the SERT/NET inhibitor duloxetine [13], which blocks the interaction of MDMA with the SERT and NET and the resulting MDMA-induced transportermediated release of 5-HT and NE [7], but were not blocked by the NET inhibitor reboxetine [13], which only blocks the MDMA-induced release of NE [45].

Additionally, MDMA and the 5-HT releaser metachlorophenylpiperazine increased plasma cortisol levels, whereas amphetamine, which activates catecholamines more similarly to methylphenidate, did not [14]. Selective activation of the 5-HT system by acute administration of the SERT inhibitor citalopram also increased plasma and salivary cortisol levels [46]. Six-day treatment with citalopram but not the NET inhibitor reboxetine also increased waking salivary cortisol levels [47]. Finally, significant associations have been reported between polymorphisms in the genes that encode the SERT and HPA axis reactivity [48]. Thus, these findings indicate a role for 5-HT in the mediation of MDMA-induced HPA axis stimulation in humans but little or no role for NE. Additionally, MDMA releases 5-HT from peripheral non-neuronal tissues directly into the blood plasma [49] and 5-HT has been shown to directly stimulate aldosterone secretion by glomerulosa cells [50].

One important issue is the clinical relevance of MDMA's effects on corticosteroids. Steroids are involved in a wide range of central and peripheral physiological functions related to mood, cognition, adaptation to stress, immune function, and others. In the context of recreational drug use, cortisol, DHEA, and testosterone may contribute to or modulate substance-induced acute psychotropic and reinforcing effects [12, 20, 21]. For example, MDMA-induced increases in plasma cortisol levels have previously been shown to correlate with subjective drug liking in response to MDMA in a laboratory study [12]. Stress-induced increases in cortisol were also correlated with positive mood responses to amphetamine [51]. Nonetheless, we found no associations between plasma steroid levels and any of the previously reported psychotropic effects of MDMA in the present study [9] or in our previous work [13]. It is possible that we missed a true association because of the small study size. It is also possible that the subjective and some endocrine responses were maximal

Neuroendocrinology 2014;100:17-25 23 
and therefore similar in most subjects (low between-subject variability). For example, such a lack of between-subjects correlations has previously been documented for correlations between MDMA plasma levels and autonomic effects [52]. The pleasurable effects of amphetamine and methamphetamine in humans also did not change when cortisol levels were increased pharmacologically [53] or lowered by metyrapone administration prior to methamphetamine administration [33]. As noted above, MDMAinduced elevations of mineralocorticoids may also contribute to regulation of the hypertensive effects of MDMA. Corticosteroids may also facilitate the development of hyperthermia associated with amphetamines, a potentially fatal complication of recreational ecstasy use $[54,55]$. In rats, adrenalectomy or administration of a glucocorticoid receptor antagonist suppressed methamphetamine- and MDMA-induced increases in body temperature [56-58]. Human data are lacking, but MDMA-induced elevations of steroids may contribute to the clinical toxicity of ecstasy $[16,29]$. Finally, repeated HPA axis stimulation by MDMA may contribute to chronic toxicity [11, 17, 29], including the deficits in neurocognitive function described in heavy ecstasy users [59].

The present study has several limitations. First, we used only single doses of the drugs. However, the selected dos- es were high and produced pronounced and comparable sympathomimetic and drug-typical psychotropic effects [9]. Second, we did not assess corticotropin-releasing factor or ACTH levels to describe the drugs' effects on other mediators within the HPA axis. Instead, we provided the full profiles of ten steroids. Specifically, we included corticosterone, which is the biologically relevant glucocorticoid in rodents, the mineralocorticoid aldosterone, and androgens, which may play a role in mood regulation.

In conclusion, the MDMA- but not methylphenidateinduced effects on plasma steroids are consistent with a role for 5-HT in drug-induced HPA axis stimulation in the absence of other (psychosocial) stressors. Remaining to be investigated are whether and how the different steroids contribute to the acute and chronic effects of these psychoactive drugs.

\section{Acknowledgements}

This study was supported by the Swiss Centre of Applied Human Toxicology (to A. Odermatt), Swiss National Science Foundation (31003A_140961 to A. Odermatt and 32323B_144996 and 320030_149493 to M.E. Liechti), and University of Basel (DPH 2064 to C.M. Hysek). We thank Nathalie Schillinger and Nicole Meyer for study management and M. Arends for manuscript editing.

\section{References}

1 Armario A: Activation of the hypothalamicpituitary-adrenal axis by addictive drugs: different pathways, common outcome. Trends Pharmacol Sci 2010;31:318-325.

-2 Swerdlow NR, Koob GF, Cador M, Lorang M, Hauger RL: Pituitary-adrenal axis responses to acute amphetamine in the rat. Pharmacol Biochem Behav 1993;45:629-637.

$>3$ Rivier C, Lee S: Stimulatory effect of cocaine on ACTH secretion: role of the hypothalamus. Mol Cell Neurosci 1994;5:189-195.

4 Sarnyai Z, Biro E, Telegdy G: Cocaine-induced elevation of plasma corticosterone is mediated by different neurotransmitter systems in rats. Pharmacol Biochem Behav 1993;45:209-214.

5 Borowsky B, Kuhn CM: Monoamine mediation of cocaine-induced hypothalamo-pituitary-adrenal activation. J Pharmacol Exp Ther 1991;256:204-210.

-6 Zhou Y, Spangler R, Yuferov VP, Schlussmann SD, Ho A, Kreek MJ: Effects of selective D1- or D2-like dopamine receptor antagonists with acute 'binge' pattern cocaine on corticotropinreleasing hormone and proopiomelanocortin mRNA levels in the hypothalamus. Brain Res Mol Brain Res 2004;130:61-67.

7 Hysek CM, Simmler LD, Nicola V, Vischer N, Donzelli M, Krähenbühl S, et al: Duloxetine in- hibits effects of MDMA ('ecstasy') in vitro and in humans in a randomized placebo-controlled laboratory study. PLoS One 2012;7:e36476.

$>8$ Han DD, Gu HH: Comparison of the monoamine transporters from human and mouse in their sensitivities to psychostimulant drugs. BMC Pharmacol 2006;6:6.

$\checkmark 9$ Hysek CM, Simmler LD, Schillinger N, Meyer N, Schmid Y, Donzelli M, et al: Pharmacokinetic and pharmacodynamic effects of methylphenidate and MDMA administered alone and in combination. Int J Neuropsychopharmacol 2014; 17:371-381.

10 Dumont GJ, Verkes RJ: A review of acute effects of 3,4-methylenedioxymethamphetamine in healthy volunteers. J Psychopharmacol 2006;20:176-187.

$>11$ Parrott AC: Cortisol and 3,4-methylenedioxymethamphetamine: neurohormonal aspects of bioenergetic stress in ecstasy users. Neuropsychobiology 2009;60:148-158.

12 Harris DS, Baggott M, Mendelson JH, Mendelson JE, Jones RT: Subjective and hormonal effects of 3,4-methylenedioxymethamphetamine (MDMA) in humans. Psychopharmacology (Berl) 2002;162:396-405.

13 Hysek CM, Domes G, Liechti ME: MDMA enhances 'mind reading' of positive emotions and impairs 'mind reading' of negative emotions. Psychopharmacology (Berl) 2012;222:293-302.

14 Tancer M, Johanson CE: Reinforcing, subjective, and physiological effects of MDMA in humans: a comparison with D-amphetamine and mCPP. Drug Alcohol Depend 2003;72:33-44.

15 Mas M, Farre M, de la Torre R, Roset PN, Ortuno J, Segura J, et al: Cardiovascular and neuroendocrine effects and pharmacokinetics of 3,4-methylenedioxymethamphetamine in humans. J Pharmacol Exp Ther 1999;290:136145.

$\$ 16$ Parrott AC, Lock J, Conner AC, Kissling C, Thome J: Dance clubbing on MDMA and during abstinence from ecstasy/MDMA: prospective neuroendocrine and psychobiological changes. Neuropsychobiology 2008;57: 165-180.

17 Wolff K, Tsapakis EM, Pariante CM, Kerwin RW, Forsling ML, Aitchison KJ: Pharmacogenetic studies of change in cortisol on ecstasy (MDMA) consumption. J Psychopharmacol 2012;26:419-428.

18 Grob CS, Poland RE, Chang L, Ernst T: Psychobiologic effects of 3,4-methylenedioxymethamphetamine in humans: methodological considerations and preliminary observations. Behav Brain Res 1996;73:103-107. 
19 Oddie CJ, Coghlan JP, Scoggins BA: Plasma desoxycorticosterone levels in man with simultaneous measurement of aldosterone, corticosterone, cortisol and 11-deoxycortisol. J Clin Endocrinol Metab 1972;34:1039-1054.

20 Mendelson JH, Mello NK, Sholar MB, Siegel AJ, Mutschler N, Halpern J: Temporal concordance of cocaine effects on mood states and neuroendocrine hormones. Psychoneuroendocrinology 2002;27:71-82.

21 Mello NK, Knudson IM, Kelly M, Fivel PA, Mendelson JH: Effects of progesterone and testosterone on cocaine self-administration and cocaine discrimination by female rhesus monkeys. Neuropsychopharmacology 2011; 36:2187-2199.

22 West CD, Mahajan DK, Chavre VJ, Nabors CJ, Tyler FH: Simultaneous measurement of multiple plasma steroids by radioimmunoassay demonstrating episodic secretion. J Clin Endocrinol Metab 1973;36:1230-1236.

23 Karssen AM, Meijer OC, van der Sandt IC, Lucassen PJ, de Lange EC, de Boer AG, et al: Multidrug resistance $\mathrm{P}$-glycoprotein hampers the access of cortisol but not of corticosterone to mouse and human brain. Endocrinology 2001;142:2686-2694.

24 Odermatt A, Kratschmar DV: Tissue-specific modulation of mineralocorticoid receptor function by $11 \beta$-hydroxysteroid dehydrogenases: an overview. Mol Cell Endocrinol 2012; 350:168-186.

25 Dotsch J, Dorr HG, Stalla GK, Sippell WG: Effect of glucocorticoid excess on the cortisol/ cortisone ratio. Steroids 2001;66:817-820.

-26 Nomura S, Fujitaka M, Jinno K, Sakura N, Ueda K: Clinical significance of cortisone and cortisone/cortisol ratio in evaluating children with adrenal diseases. Clin Chim Acta 1996; 256:1-11.

27 Simmler LD, Hysek CM, Liechti ME: Sex differences in the effects of MDMA (ecstasy) on plasma copeptin in healthy subjects. J Clin Endocrinol Metab 2011;96:2844-2850.

28 Henry JA, Fallon JK, Kicman AT, Hutt AJ, Cowan DA, Forsling M: Low-dose MDMA ('ecstasy') induces vasopressin secretion. Lancet 1998;351:1784.

29 Parrott A, Lock J, Adnum L, Thome J: MDMA can increase cortisol levels by $800 \%$ in dance clubbers. J Psychopharmacol 2013;27:113-114.

30 Brown WA, Corriveau DP, Ebert MH: Acute psychologic and neuroendocrine effects of dextroamphetamine and methylphenidate. Psychopharmacology (Berl) 1978;58:189-195.

-31 Van Kempen GM, Goekoop JG, Jong HB Edelbroek PM, de Wolff FA: The plasma level of methylphenidate in the single-dose oral methylphenidate test. Biol Psychiatry 1990; 28:638-640.

- 32 Joyce PR, Donald RA, Nicholls MG, Livesey $\mathrm{JH}$, Abbott RM: Endocrine and behavioral responses to methylphenidate in normal subjects. Biol Psychiatry 1986;21:1015-1023.

-33 Harris DS, Reus VI, Wolkowitz OM, Mendelson JE, Jones RT: Altering cortisol level does not change the pleasurable effects of metham- phetamine in humans. Neuropsychopharmacology 2003;28:1677-1684.

34 Jayaram-Lindstrom N, Konstenius M, Eksborg S, Beck O, Hammarberg A, Franck J: Naltrexone attenuates the subjective effects of amphetamine in patients with amphetamine dependence. Neuropsychopharmacology 2008;33:1856-1863.

35 Sofuoglu M, Poling J, Hill K, Kosten T: Atomoxetine attenuates dextroamphetamine effects in humans. Am J Drug Alcohol Abuse 2009;35:412-416.

36 White TL, Grover VK, de Wit H: Cortisol effects of D-amphetamine relate to traits of fearlessness and aggression but not anxiety in healthy humans. Pharmacol Biochem Behav 2006;85:123-131.

37 Hill SA, Taylor MJ, Harmer CJ, Cowen PJ: Acute reboxetine administration increases plasma and salivary cortisol. J Psychopharmacol 2003;17:273-275.

38 Hennig J, Lange N, Haag A, Rohrmann S, Netter P: Reboxetine in a neuroendocrine challenge paradigm: evidence for high cortisol responses in healthy volunteers scoring high on subclinical depression. Int J Neuropsychopharmacol 2000;3:193-201.

39 Maayan R, Yoran-Hegesh R, Strous R, Nechmad A, Averbuch E, Weizman A, et al: Threemonth treatment course of methylphenidate increases plasma levels of dehydroepiandrosterone (DHEA) and dehydroepiandrosterone-sulfate (DHEA-S) in attention deficit hyperactivity disorder. Neuropsychobiology 2003;48:111-115.

40 Martin WR, Sloan JW, Sapira JD, Jasinski DR: Physiologic, subjective, and behavioral effects of amphetamine, methamphetamine, ephedrine, phenmetrazine, and methylphenidate in man. Clin Pharmacol Ther 1971;12:245-258.

41 Rush CR, Essman WD, Simpson CA, Baker RW: Reinforcing and subject-rated effects of methylphenidate and D-amphetamine in non-drug-abusing humans. J Clin Psychopharmacol 2001;21:273-286.

42 Sommers DK, van Wyk M, Snyman JR: Dexfenfluramine-induced prolactin release as an index of central synaptosomal 5-hydroxytryptamine during treatment with fluoxetine. Eur J Clin Pharmacol 1994;46:441-444.

43 Nash JF Jr, Meltzer HY, Gudelsky GA: Elevation of serum prolactin and corticosterone concentrations in the rat after the administration of 3,4-methylenedioxymethamphetamine. Pharmacol Exp Ther 1988;245:873-879.

44 Zaretsky DV, Zaretskaia MV, Dimicco JA, Durant PJ, Ross CT, Rusyniak DE: Independent of 5-HT1A receptors, neurons in the paraventricular hypothalamus mediate ACTH responses from MDMA. Neurosci Lett 2013;555:42-46.

45 Hysek CM, Simmler LD, Ineichen M, Grouzmann E, Hoener MC, Brenneisen R, et al: The norepinephrine transporter inhibitor reboxetine reduces stimulant effects of MDMA ('ecstasy') in humans. Clin Pharmacol Ther 2011;90:246-255.
46 Bhagwagar Z, Hafizi S, Cowen PJ: Acute citalopram administration produces correlated increases in plasma and salivary cortisol. Psychopharmacology (Berl) 2002;163:118-120.

47 Harmer CJ, Bhagwagar Z, Shelley N, Cowen PJ: Contrasting effects of citalopram and reboxetine on waking salivary cortisol. Psychopharmacology (Berl) 2003;167:112-114.

48 Miller R, Wankerl M, Stalder T, Kirschbaum C, Alexander N: The serotonin transporter gene-linked polymorphic region (5-HTTLPR) and cortisol stress reactivity: a meta-analysis. Mol Psychiatry 2013;18:1018-1024.

49 Yubero-Lahoz S, Ayestas MA Jr, Blough BE, Partilla JS, Rothman RB, de la Torre R, et al: Effects of MDMA and related analogs on plasma 5-HT: relevance to 5-HT transporters in blood and brain. Eur J Pharmacol 2012;674:337-344.

50 Shenker Y, Gross MD, Grekin RJ: Central serotonergic stimulation of aldosterone secretion. J Clin Invest 1985;76:1485-1490.

51 Hamidovic A, Childs E, Conrad M, King A, de Wit H: Stress-induced changes in mood and cortisol release predict mood effects of amphetamine. Drug Alcohol Depend 2010; 109:175-180.

52 Hysek CM, Liechti ME: Effects of MDMA alone and after pretreatment with reboxetine, duloxetine, clonidine, carvedilol, and doxazosin on pupillary light reflex. Psychopharmacology (Berl) 2012;224:363-376.

53 Wachtel SR, Charnot A, de Wit H: Acute hydrocortisone administration does not affect subjective responses to $\mathrm{D}$-amphetamine in humans. Psychopharmacology (Berl) 2001; 153:380-388.

54 Henry JA, Jeffreys KJ, Dawling S: Toxicity and deaths from 3,4-methylenedioxymethamphetamine ('ecstasy'). Lancet 1992;340:384387.

55 Liechti ME, Kunz I, Kupferschmidt H: Acute medical problems due to ecstasy use. Caseseries of emergency department visits. Swiss Med Wkly 2005;135:652-657.

56 Herring NR, Gudelsky GA, Vorhees CV, Williams MT: (+)-Methamphetamine-induced monoamine reductions and impaired egocentric learning in adrenalectomized rats is independent of hyperthermia. Synapse 2010; 64:773-785.

57 Makisumi T, Yoshida K, Watanabe T, Tan N, Murakami N, Morimoto A: Sympatho-adrenal involvement in methamphetamine-induced hyperthermia through skeletal muscle hypermetabolism. Eur J Pharmacol 1998;363: 107-112.

58 Fernandez F, Aguerre S, Mormede P, Chaouloff F: Influences of the corticotropic axis and sympathetic activity on neurochemical consequences of 3,4-methylenedioxymethamphetamine (MDMA) administration in Fischer 344 rats. Eur J Neurosci 2002;16:607-618.

59 Rogers G, Elston J, Garside R, Roome C, Taylor R, Younger $\mathrm{P}$, et al: The harmful health effects of recreational ecstasy: a systematic review of observational evidence. Health Technol Assess 2009;13:iii-iv, ix-xii, 1-315.
Effects of MDMA and Methylphenidate on Steroid Hormones
Neuroendocrinology 2014;100:17-25 DOI: $10.1159 / 000364879$ 